\title{
VORWORT ZUR DEUTSCHEN AUFLAGE
}

In der deutschen Ausgabe dieses Buches wurden Ergänzungen eingefügt, die für die zweite russische Auflage erarbeitet worden sind. Leider war durch die Krankheit nach einem tragischen Autounfall nicht die Möglichkeit gegeben, mit meinem Lehrer und Freund L. D. LANDAU gemeinsam diese Ausgabe vorzubereiten.

Außer einigen Berichtigungen und Zusätzen wurde das Buch durch ein neues Kapitel über die makroskopische Theorie der Versetzungen ergänzt. Dieses Kapitel wurde zusammen mit A. M. Kosewrtsch verfaßt, dem ich an dieser Stelle für seine Hilfe herzlich danken möchte.

Beim Studium des Buches im Umfange eines ,theoretischen Minimums" für theoretische Physiker kann man empfehlen, die Paragraphen 8, 9, 11-21, 25-31 auszulassen.

Ich möchte die Gelegenheit benutzen, auch im Namen meines Mitautors L. D. LANDAU, dem Übersetzer und den Herausgebern der deutschen Ausgabe für die Sorgfalt und Aufmerksamkeit zu danken, die sie bei der umfangreichen Arbeit an der Übersetzung unseres Lehrbuches der theoretischen Physik angewendet haben.

Wir danken weiter dem Akademie-Verlag, der bei der Herausgabe dieses Buches immer unseren Wünschen entgegengekommen ist.

Moskau, Mai 1965

E. M. Lifschitz 